\title{
INFLUENCE OF RESOURCE ALLOCATION AND INNOVATION ON PROFITABILITY OF MICRO SMALL AND MEDIUM ENTERPRISES (MSMES) IN IN KENYA: A SURVEY OF KAMUKUNJI IN NAIROBI CITY COUNTY
}

\author{
Irene Naipande Kisaka ${ }^{a}$, Brown Kitur ${ }^{b}$ \\ a Department of Business Administration, The Manageent University of Africa, \\ P Ob Box 29677-00100 Nairobi Kenya \\ ${ }^{\mathrm{b}}$ Deaprtment of Business Administration, The Management University of Africa, \\ P.O Box 29677 -00100, Nairobi Kenya. \\ anaipande1@gmail.com; b bkitur@mua.ac.ke
}

\begin{abstract}
This paper sought to explore the strategic management practices and profitability of micro small and medium enterprises. The main focus of the study was to assess influence of resources allocation and innovation on the profitability of micro, small and micro enterprises. The study adopted descriptive design where the population of the study was 1123 MSMEs and stratified random sampling techniques was applied to pick a sample of 112 MSMEs operating in central district business in Nairobi. The researcher used questionnaire to collect data. Moreover, a total of 112 questionnaires were distributed to business owners and managers of MSMEs in operating in Kamukunji in Nairobi County. Data was analyzed using both inferential statistics through regression, and descriptive statistics in the form of frequencies and percentages. The study found out that resource allocation positively and significantly influenced the profitability of MSMEs, innovation was found to positively and statistically significant influence on profitability of MSMEs, the study established that strategic leadership had a positive and significant effect on profitability of MSMEs. In addition, the study also established that strategic human resource was found to be positively related and statistically significant to profitability of micro small and medium enterprises. The study concluded that resource allocation and innovation had a significant effect on profitability of MSMEs. The study recommends that MSMEs should establish effective management and optimization of resource allocation since enterprises do not have unlimited access to resources. Moreover, study recommends that MSMEs should embrace various form innovations including product innovation, marketing innovation, process innovation and organization innovation which a considered as key driver of performance of MSMEs so that they can compete effectively with larger firms.
\end{abstract}

Key words: resources allocation, innovation, profitability 


\subsection{Introduction}

Micro, small and medium Enterprises (MSMEs) are major driver of economic development (Obi et.al, 2018), being crucial to majority of economies across the globe, especially in emerging and developing countries (Ndiaye et.al, 2018). Globally, MSMEs not only make up of the bulk of enterprises worldwide but are also significant creator of jobs opportunities and country's economic prosperity. MSMEs make up roughly $90 \%$ of enterprises and account for greater than $50 \%$ of jobs created in the world. Besides, formally registered MSMEs partly accounts for $40 \%$ of the GDP in developing countries. The figures are considered to be even higher when unlicensed firms are taken into account. These MSMEs constitutes a sizeable portion of aggregate employment, job creation, and GDP in many emerging economies. Report by World Bank, (2019) indicates that formal MSMEs provides approximately 60 percent of aggregate employment, about 80 percent of new formal job creation, and up to $40 \%$ of gross domestic product (GDP) in developing states, excluding informal enterprises.

The potential of smaller businesses in fostering socio-economic growth in developed and emerging economies is universally acknowledged and documented by both academicians and policy makers. For instance, in the European Union, it accounts for over $99 \%$ of all businesses in these countries. Nearly $91 \%$ of these businesses can be regarded as smaller enterprises engaging less than 10 employees. They continue to distribute their potentiality in all sectors of the economies. The growth of MSMEs was, for instance, played a critical role in the economic recovery of the 2008 global crisis (EU, 2011). Inadequate financing of small businesses mostly in developing nations has been pinpointed as a major hurdle in realizing the potential of these critical sector. Bank financing is among the best options to be employed to bridge the funding gap facing MSMEs sector given the fact that are the driving force of the industrial growth and in most of the developing countries.

Presently, businesses operate in a very competitive environment which has dramatically forced enterprises to craft complex decisions for competitive strategic management (Muogbo, 2013). According to Haines (2016), competitive Strategic management practices entails the devising and execution of the important objectives and strategic initiatives by top managers taking into account the firm's resources and operating environments in which the business exists. The managements are mandated to devise sound strategies that will ensure that the organization remains float despite the turbulent market. According to Owolabi and Makinde (2012) the ability to make above average profitability depends on the competitive strategies employed by the entity. Furthermore, market competition is nothing more than just outwitting the competition and gaining customers by bundling more value on the product or service being offered. Strategic plan is a company-wide orientation involving different people performing various tasks all geared to offer organization general direction on its performance (Brycesson \& Slaughter 2011). The definitive intention of management practices is to ensure the organization as a whole collectively defines the organization vision and projects the mission that characterizes the organization strategic direction.

According to Yazdanfar (2013), opine that profitability is a primary prerequisite for sustained long-term business survival and success. The success and other financial objectives are considerably influenced by the profit attained. Performance refers to how best a firm is able to accomplish tasks as benchmarked against predetermined standards. At the outset of every accounting cycle, firms usually deliberately decide on the goals or objectives they intend to achieve. In other economies, MSMEs Performance has been evaluated satisfactorily by way of profitability index and employment growth (Chirwa, 2008). Profitability is crucial element that 
determines firm's survival in a competitive business situation. Long-term profits is achieved through cost minimization and revenue maximization; though this is important, it is not an outright guarantee for sustainable growth. Revenues can be improved by imposition of entry barriers and costs can be effectively contained through manager's financial expertise. However, a poorly planned and executed strategies move could lead to loss of millions of dollars, thousands of jobs jeopardized or even business to be bankrupt (Kazmi, 2008).

\subsection{Statement of the Problem}

The significance of MSMEs has taken center stage in economic development and especially in developing economies like Kenya. However, MSMEs entrepreneurs encounter many unique challenges than larger enterprises in the course of operations. In majority of enterprises, the adoption of business strategies need a lot investment in term of resources and time to initiate the necessary changes in the organizational culture and structure hence most of the business managers often ignore these critical business strategies (Gure \& Karugu, 2018). In response to these challenges, strategic management practices have emerged as an antidote to help businesses improve their profitability relative to their competitors so as to remain afloat in the backdrop of environmental uncertainty. The incorporating strategic management practices ideally help organization to discover their strategic position, make strategic choices and manage strategy in action.

Deploying strategic management is of significance to firm's performance (Johnson et al., 2008). In fact, theoretical and empirical evidence affirms that several benefits accrue from embracing superior strategies that potentially enhances the organization profitability. The deployment of superior strategic management initiatives provides small enterprises with improved techniques that enable survival, growth and build sustainable competitive advantage (Omerzel \& Antoncic, 2008). Furthermore, strategic planning forces MSMEs to adapt to become more proactive in a bid to survive the changing environment. Markets are never static thus MSMEs must initiate and adopts new business strategies to ensure shore up profitability. The marketplace is ever dynamic as a result of constant change in consumer behavior and needs, global competition and new markets entrants. In Kenya, Karanja et al (2013) purposed to analyze the effect of innovations on growth of MSMEs in Nairobi County and the findings indicated that innovations played a key role in the growth of firm. Burugo and Owour (2017) in the research planned to find out the influence of strategic management practices on business profitability in Chai trading limited in which they revealed that general organizational performance was positively affected by strategic management practices. Majority of the studies have reviewed performance on a wide spectrum and the issue of resource allocation and innovation as part of the strategic management practices may have been left out and therefore the study sought to establish the influence of resource allocation and innovation on profitability of micro, small and medium enterprises (MSMEs).

\subsection{Specific Objective of the Study}

i. To examine the extent to which resource allocation influence the profitability of micro small and medium enterprises

ii. To assess the extent to which innovation influences the profitability of micro small and medium enterprises

\subsection{Scope of the Study}


The study was confined to the investigation of management practices and profitability of micro small and micro enterprises (MSMEs) in Kenya. The period of the study ranged from ${ }^{\text {st }}$ August 2020 to $30^{\text {th }}$ March 2021. This ensured that the result captured current issues in the market regarding MSMEs. In addition, the study targeted 1123 MSMEs operating in Kamukunji in Nairobi County as result of time and financial constraint. Furthermore, it was impossible to study the whole population within limited period of time. The study was undertaken within a period of seven months.

\subsection{Literature Review}

\subsection{Theoretical Framework}

This paper was anchored on dynamic capability theory supported by Resource-based View theory.

\subsubsection{Dynamic Capability Theory}

This paper was anchored on the Dynamic capabilities (DC) theory is an extension from RBV theory that was developed to provide an insight and attempt to explain sustained competitive edge and higher performance in ever changing environment. This concept was first introduced by Teece, Pisano and Shuen (1997), in their work entitled "Dynamic Capabilities and Strategic Management". In the context of organizational theory, dynamic capability is connotes the ability of the enterprise to deliberately adapt and spur firm's asset base. According to Teece et al. (1997), dynamic capabilities represent "an enterprise's ability to merge, augment and redesign internal and outside competencies in order to cope in fast-paced business environments characterized by uncertainties and volatility". Dynamic capabilities therefore represents the organizational and strategic routine activities through which enterprises attains new resource configurations as markets emerge, collide, split, evolve and die" (Eisenhardt \& Martin, 2000). The major assumption of DC models is that enterprise's fundamental competencies can be employed to build short-term advantage that can be changed into longer-term advantage.

Teece (2007) in his work identified the basis for each of the major constructs: sensing (scanning the environment for opportunity), seizing (deploy resources to seize an opportunity and to realize benefits) and modification (continued renewal "redesigning the enterprise's intangible and tangible resources). Dynamic capabilities represent critical segment of innovation capacity because they aid to enable, enhance and reconfigure the firm' resources mix and capabilities in volatile business environments (Teece, 2007).Moreover, sustained modification, development and revaluation constitutes a major challenge for firms that operate in innovative and competitive markets against backdrop of volatile environment coupled with market velocity and uncertainty. Generally speaking, innovation capability can be theoretically regarded as a firm's bundle of resources, capabilities and dynamic capabilities deliberately directed towards innovation process.

The dynamic capabilities theory is important to this study because the MSMEs must be in a position to identify the opportunities and threats in their environment, seize these opportunities and maintain competitiveness in the face of the changing business environment. The application of Dynamic Capabilities aids in formulating the strategic paths that determines the organization strategy and eventually competitive advantage to be enjoyed. The theory offers path-dependent activity that enables organization of all forms and shapes to react swiftly to changing condition by creating, integrating and reconfiguring their critical resource and capabilities bundles.

\subsubsection{Resource-based View Theory}


The resource-based view (RBV) is a managerial tool employed to assess the strategic assets an enterprise can harness to attain sustained competitive edge. The RBV borrows heavily from theory of firm growth developed by Penrose (1959) and concept of resources postulated by Wernerfelt (1984).Thereafter, Barney (1991) formalized the concept of RBV into a theoretical framework while attempting to gain an insight of the effect of an enterprise's environment on firm performance (Newbert, 2007).According to Barney (1991), resources may be termed as "assets, capacity, processes, features, information and knowledge within the control of an enterprise that aids it devise ideas and execute game plan that bolster its operational efficiency and effectiveness". Amit and Schoemaker (1993) grouped enterprise resources into three broad classifications namely physical assets, human capital and organizational capital. These resources are regarded as strategic resource because they improve competitive advantages of the firm. A strategic resource is an asset that possesses unique features; that is valuable, infrequent, hard to copy, and non-replaceable.

The theory is anchored on two assumptions, i.e. that resources are not necessarily homogeneous dispersed among enterprises and secondly that these assets usually not perfectly mobile (Barney, 1991). In other words, enterprises are not homogeneous because they own heterogeneous assets and therefore firms can adopt varied strategies because they possess different resource mixes. The idea of joint assumptions accounts for the differences in enterprise resources endowments to both exist and remain in existence over the period (Newbert, 2007). The RBV implication is that managers must pay attention on the enterprises' internal resources in order to highlight those assets, capabilities and competencies with great ability to attain excellent outcomes. The resource based theory is a very important tool which enable managers to in establish resources owned by a firm and link them with the capabilities of the organization in a silent process. It brings into focus the profitability and the benefits factor connected with the firm. The theory is anchored on the idea that competitive advantage can be achieved when a firm is able to deploy its key assets in distinct and effective manner than its counterparts in the market.

\subsection{Empirical Studies}

\subsubsection{Resource Allocation}

According to Hitt et a 1, (2011) resources are a major source for enterprise performance. Every so often firm's resources require being configured, reconfigured, co-evolved, harmonized and redesigned for appropriate utilization thereby causing higher performance and competitive advantage (Pearce et al.2013). Effective allocation of enterprises' resources is a pivotal role in the effective execution of strategy. Strategic management basically works towards situating the organization's internal resources against the external opportunities present in the environment so as to accomplish the strategic goal of the business. Enterprises' internal resources consists of financial resources, physical assets, human capital, and firm intangible resources that include the group cohesion, the planning, organization's structure and controls, culture and reputation of the enterprises. Most SMEs are believed to be faced with resource constraints from the initial stage through growth phase. Management should also assess the extent to which deviations to these measures arise following changes in the business attractiveness. Since most budgets will be based on cost centered operating departments, it is recommended to include key non-monetary factors that would act as indicators of whether the strategic programs initiated are proceeding on schedule.

Nyandara, Ngacho, and Yambo (2017) in their study purposed to establish the effects of resource allocation on the performance of South Nyanza Sugar Co.Ltd. This study involved use of descriptive research design where 329 respondents were identified out of 994 of South Nyanza 
Sugar Company being the target population. Both purposive and stratified random sampling were used to select the sample. Both primary and secondary data were obtained through the use questionnaires and documentary respectively. The study revealed that resource allocation was found to have high effects on the performance and that effective management of resource allocation could lead to better performance.

Mwai, Namada and Katuse (2018) in their work sought to establish influence of organizational resources on organizational effectiveness. The population consisted 5547 managers of NGOs registered in Nairobi. Specifically the 374 project managers included in the final sample were selected by simple random sampling technique. Simple random sampling reduced bias and gave each NGO in Nairobi a chance to participate. Based on the findings, organizational resources depicted a positive and significant relationship with organizational effectiveness and that fundraising efforts positively impacted on the efficiency of organizational processes. The allocation of resources leads to positive influence on an organization's capability to attain its organizational strategy and objectives.

Mutiso, Ngugi, and Senaji (2016) also sought to find out the role of resource allocation on promotion of Intrapreneurship in MSMEs in Kenya. The study was conducted using both correlational and descriptive research survey design. SMMEs from a sample of 254 firms derived using Krejcie and Morgan (1970) table. Using random sampling, 145 firms responded and out of these 133 were found to be SMMEs. The primary data for the study was collected from 114 SMMEs who successfully participated using random sampling, 145 firms responded and out of these 133 were found to be SMMEs. The final data for the study was collected from 114SMMEs who successfully participated. In their study, they employed a structured set of questions to gather first-hand data on the whole target population. The data analysis conducted using both descriptive and inferential statistics. The findings demonstrated the presence of a high positive effect of allocation of resources on entrepreneurship as depicted by high R-square.

Sang, Kirui and Langat (2021) explored the effect of organizational resources on strategy implementation in Faith-based organizations and purposed to establish human capital, financial resources, information systems resources and organizational structure on strategy implementation in Tenwek Hospital. A case study design that considered forty managerial staff at Tenwek Hospital. The researcher collected primary data using census approach. Questionnaire formed the key instrument for collecting first hand data. The results of the study indicated the presence of positive significant correlation between human resources and strategy implementation, financial resources and strategy implementation, information system resources and strategy execution and between organizational structure and strategy implementation.

\subsubsection{Innovations}

Innovation is the major strategy that is driving firms' growth and survival in any competitive business environment. The introduction of novel products and services has become the thrust behind the launch pad for new SMEs and the growth of the present ones. Thus for firms survival and growth, innovation has become a necessity for all firms including SMEs. According to Hitt et al., (2001), innovations provide enterprise with a strategic direction to counter the problems organizations face in their effort to gain sustained competitive edge. Innovation is not just a word related to product offering and organizational processes, but also encompasses marketing and organization aspects. Schumpeter (1934) highlights various forms of innovation: brand new products, latest techniques of production, newly discovered sources of supply, the taking 
advantage of current markets, and the most updated means of organizing business. Firms that allocate adequate resources to enhance innovation ability can greatly result to surge in production and higher market performance, so enterprises should strive to bolster innovation capabilities (Gunday et al., 2009). Kong, and Masud, (2020) in their scholarly paper titled "'innovation capabilities, innovation types, and firm performance" sought to identify the impact of innovation adoption on performance of banks in Ghana. The study obtained data from a pool of 450 respondents that included both employees and customers of the bank in Kumasi metropolitan. Results revealed that the innovation aspects that significant plays part in bank innovation are organizational, product, process, and marketing innovations. The results also showed a direct and positive relationship between innovation in term of product, marketing, and organizational innovations, and bank performance. Moreover, outcomes of the study revealed a positive relationship between innovation capability and the four aspects of innovation that included organizational, product, process, and market innovations. In summary, the study demonstrated that selecting a suitable innovation kind can foster bank performance and at the same enhance customer satisfaction.

A study by Mohammad,Sameer, Diaa,Ahmed, Ahmad, Amer, Mahmoud and Tamer,(2020) analyzed the effect of process innovation on business performance and role of design management in Malaysia. The key objective was to analyze the mediating influence of design management on the relationship between process innovation and business performance of product industries. This study employed quantitative research design approach and collected information from 386 participants from the product industries. The needed data was collected by means of questionnaire through simple random sampling techniques. The results depicted a significant association between process innovation and design management with business performance and that design management mediate the relationship between process innovation and business performance of product industries.

Martin and Namusonge (2014), carried out a study to establish the influence of technological, product and process innovations on growth of garment manufacturing industries in Nakuru. This study sought to identify how technological, product and process innovations influence the growth of garment manufacturing industries in Nakuru. The study adopted a cross section descriptive survey. A sample of 46 respondents were selected using stratified random sampling and purposive sampling techniques from a population of nine firms. The outcomes revealed that $43 \%$ of the firms had embraced latest technologies and deployed technologies in their operations, products and service, and that technological innovation was critical to the growth of the firms. The results also showed that innovating new products is key component that assist the businesses to achieve higher sales and consequently growth. Additionally, technology is was found to important in creating new methods of production that help businesses to contain cost. Overall, the study found a strong association between innovation and growth of businesses.

Kimathi, Mukulu and Odhiambo (2019) analyzed the effect of innovation on the performance of Small and Medium enterprises in Kenya. The population of this study comprised of 268,100 licensed businesses. A sample of 400 SMEs from seventeen constituencies were picked using a multi-stage probability sampling technique. The study revealed that innovation had positive and significant impact on the performance of small and medium sized business units. The study also concluded that deployment of modern innovations in production, process improvement and marketing process distinguishes performing and sustainable smaller businesses from the pool.

\subsection{Conceptual Framework}


Conceptual framework is a diagrammatic representation showing the hypothesized association between variables of study. In this study, it illustrates the interaction between resource allocation, and innovation as independent variables and profitability of small and micro enterprises as the dependent variable as shown in Figure 1.

Independent Variable

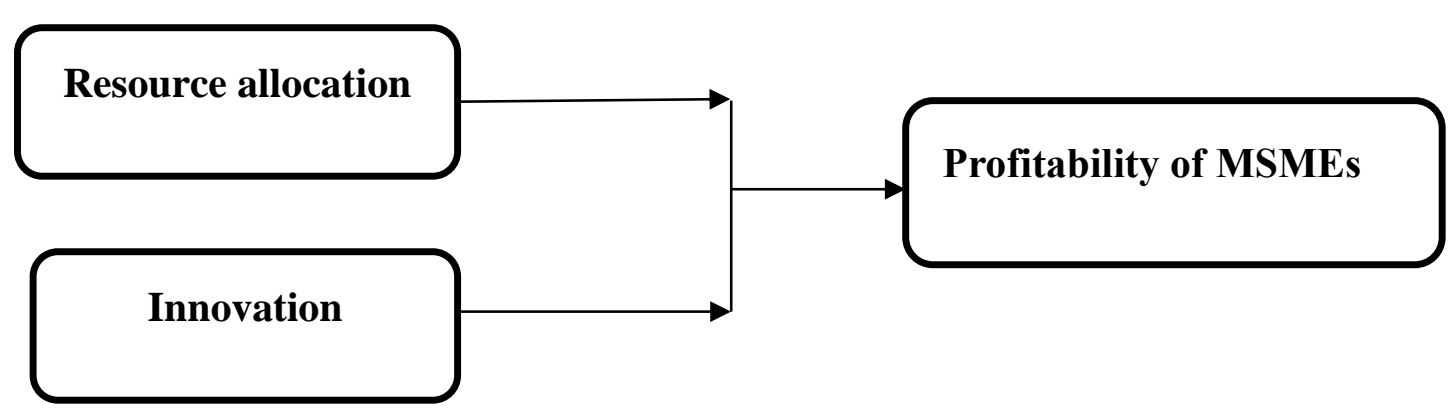

Figure 1: Conceptual Framework

\subsection{Research Methodology}

\subsection{Research Design}

Kothari (2014), defined research design as a comprehensive roadmap that is adopted to guide research study towards its objectives in obtaining responses to the inquiry. The design becomes important in deciding on the suitable method that can adequately answers to the research problem being investigated. Explanatory research attempts to explain why certain phenomena work in the way that they do is; carried out in order to identify the extent and nature of cause-and-effect relationships. Bunyasi, (2015) points out that explanatory design is appropriate when understanding the relationship between variables. The researchers therefore adopted explanatory design as the best choice needed to meet its objectives.

\subsection{Target Population}

Mugenda and Mugenda (2013) defined population as an entire set of events or objects exhibiting particular observable features, the aggregate of which has similarities with definite specifications. The target population comprised of approximately 1123 MSMEs. In this case, the target population consisted of the MSMEs operating in Kamukunji in Nairobi County.

\subsection{Sample Population}

According to Mugenda and Mugenda (2013), a sample is a smaller portion of the group from which the research draws its findings about the overall population. The research used stratified random sampling; the basis of this choice is in its ability to assemble the sample by increasing the probability of each stratum being represented in the final sample. The main study groups were MSME's in various categories ranging from wholesale shops, clothing, pharmacies, restaurants, butcheries to retail shops. The sample of $10 \%$ of the total population was considered reasonable for a conclusion to be drawn, Mugenda and Mugenda (2013), notes that a sample of $10 \%$ and 30\% 
is considered a good indicative where the population is less than 10, 000.The study applied $10 \%$ that translated to 112 MSMEs that were included in the final sample.

\subsection{Data Collection Instruments}

This study used primary data that was collected by way of questionnaire. A questionnaire simply consists of written questions that respondents are required to provide answer on the space provided. The researcher collected data from owners/manager of MSMEs using semi structured questions. The data was congregated using set of pre-written questions which were primarily distributed to the interviewees through electronic media (email). The questionnaires were framed to contain questions that reflected the study's variables. Closed questions were used in collecting views, opinions, and attitudes of respondents (Kothari, 2014).

\subsection{Data Analysis and Presentation}

The study employed SPSS software version 27.0 to analyze the data. Tables and charts were used explain the findings since they simplify results in a more understandable form. All diagrams bore tags so that the users could swiftly grasp the information being relayed. Various forms of measure of central tendency and dispersion were used to express descriptive statistics. The specific measurement used included mean, standard deviation, and frequency tables.

In order to derive inferential statistics, the research adopted multivariate regression analysis to find out the association among variables under consideration. The study statistical model involved four independent variables and one dependent variable.

The model assumed the expression:

$Y=\beta_{0}+\beta_{1} X_{1}+\beta_{2} X_{2}+\varepsilon i$

Where: $Y=$ Profitability, $X_{1}=$ Resource Allocation, $X_{2}=$ Innovation

$\beta 0=$ the intercept (value of $Y$ when $X=0$ ), $\varepsilon i=$ error term

\subsection{Research Findings and Discussion}

\subsection{Response Rate}

The researcher distributed 112 questionnaires and obtained a response of that 87 respondents. The study posted a response rate of $77.68 \%$. This higher response rate was attained through constantly engaging the respondents through telephone calls and SMS reminders to fill and submit their questionnaire. The other portion of about $22.32 \%$ non-response rate was a results of health crisis occasioned by ministry of health protocols concerning Covid 19 pandemic and general reluctance of the respondents to take part in the study. The study' return rate of $77.68 \%$ is in line with recommendation of Kothari (2014) that a response rate of at least 50\% is a good indicator for analysis and for drawing conclusions for generalization of the study.

Table 1: Return Rate 


\begin{tabular}{lll}
\hline Response & Frequency & Per cent \\
\hline Response & 87 & 77.68 \\
No response & 25 & 22.32 \\
Total & $\mathbf{1 1 2}$ & $\mathbf{1 0 0 . 0}$ \\
\hline
\end{tabular}

\subsection{Reliability Results}

The items of every study variables in the questionnaire were put through Cronbach's test and the Cronbach's alpha coefficient of the items under inquiry were way above the recommended benchmark of 0.7 . The outcome of pilot test revealed that resource allocation exhibited a Cronbach alpha coefficient of 0.7440 and innovation had a Cronbach alpha of 0.854 . From the study results proved that all the items of the variables exhibited an alpha value higher than the acceptable threshold of 0.70 .

Table 2: Reliability Analysis Results

\begin{tabular}{|c|c|c|c|c|}
\hline Scale & $\begin{array}{l}\text { No. of } \\
\text { Respondents }\end{array}$ & $\begin{array}{l}\text { No. of } \\
\text { Items }\end{array}$ & Cronbach'sAlpha & Decision \\
\hline $\begin{array}{l}\text { Resource } \\
\text { Allocation }\end{array}$ & 20 & 5 & 0.7440 & Reliable \\
\hline Innovation & 20 & 6 & 0.854 & Reliable \\
\hline
\end{tabular}

\subsection{Gender of the Respondents}

The study findings show that most of the interviewees $(55.2 \%)$ were females while $44.8 \%$ were females. The results impliedly show that the two genders were well represented in this study and therefore the findings portrayed gender balance in participating in MSMEs market.

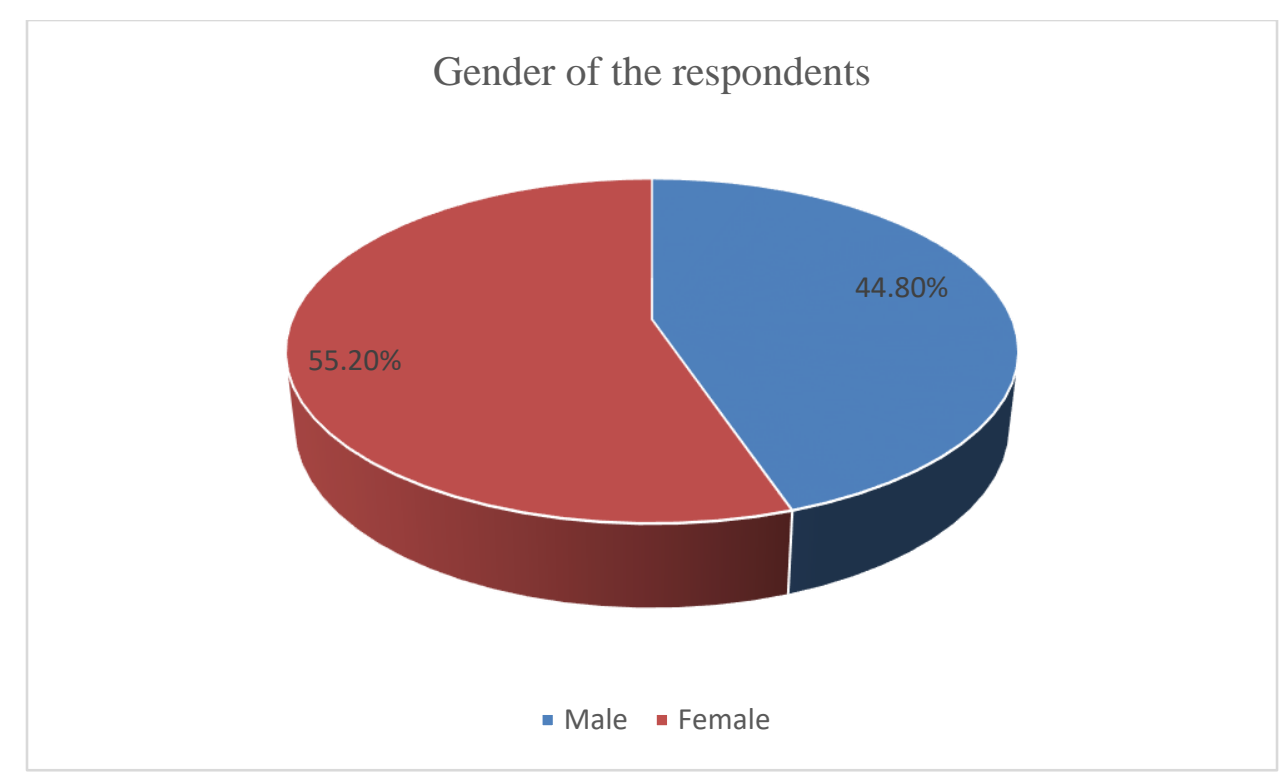




\section{Figure 2: Gender of the Respondents}

\subsection{Descriptive Analysis}

\subsubsection{Resource Allocation and Profitability of MSMEs}

From the study results in table 8 , slighlt less than to half of the respondents $(46 \%)$ indicated that the level of resource allocation in the MSMEs was moderate, and $25.30 \%$ respondents indicated that degree of resource allocation in the MSMEs was low. Besides, 38.70\% respondents indicated that level of resource allocation in the MSMEs was high. This results signifies that most of the enterprises find it hard to allocate its resources to various use since these limited resources. The findings of this study concurred with Rauf (2012), that in order to attain superior performance, the entrepreneur ought to deploy the scarce enterprises' resources efficiently and effectively to lead to attainment of competitive advantage in a sustainable way.

Table 3: The Level of Resource Allocation in the MSMEs

\begin{tabular}{lll}
\hline & Frequency & Percent \\
\hline Very high & 16 & 18.40 \\
High & 9 & 10.30 \\
Moderate & 40 & 46.00 \\
Low & 22 & 25.30 \\
Total & $\mathbf{8 7}$ & $\mathbf{1 0 0 . 0}$ \\
\hline
\end{tabular}

The study findings in Table 4 illustrated that $44.80 \%$ of the respondents indicated that MSMEs were moderately resourced and $42.50 \%$ of the respondents indicated that MSMEs were adequately resourced. However, $12.70 \%$ of the interviewees stated that MSMEs were inadequately resourced. The analysis partly confirms findings of McConnell, Brue, and Flynn (2011) that resources are critical aspect or supplies from which value is derived. Resources include materials, funds, employees, and other intangible assets requisite for effective operation of the enterprise.

Table 4: The Resource Capability of the MSMEs

\begin{tabular}{lcc}
\hline Statement & Frequency & Percent \\
\hline Adequately Resourced & 37 & 42.50 \\
Moderately resourced & 39 & 44.80 \\
Inadequately resourced & 11 & 12.70 \\
Total & $\mathbf{8 7}$ & $\mathbf{1 0 0 . 0}$ \\
\hline
\end{tabular}


The results presented in table 5, showed that most of the participants strongly agreed that resources are crucial element for the successful execution of strategic plan and strategies( $\mathrm{M}=4.092, \mathrm{SD}=1.147)$, effective management of resource allocation could lead to better performance $(\mathrm{M}=4.069, \mathrm{SD}=1.179)$ and that the MSMEs have adequate physical and human resources to promote organizational performance $(\mathrm{M}=3.505, \mathrm{SD}=1.256)$. On the othe other hand, the study, a sizeable number of the interviewees neither agree nor disgreed that it is possible to execute a strategy when resources are inadequate $(\mathrm{M}=2.885, \mathrm{SD}=1.261)$ and that resource allocation is time consuming and costly( $\mathrm{M}=2.744, \mathrm{SD}=1.356)$. The findings conform with Carlsson (2004), that organizations attains performance by managing internal resources effectively.The organization manages the internal factors by availing resources and ensuring the resources are utilized responsibly and correctly. This is further collaborated by Mutiso, Ngugi, and Senaji (2016) who argued that organizations allocate resources to improve their management innovation. The outcomes concurs with the findings of King (2007) who observed that capabilities significantly influences firms performance and competitive abililty.

Table 5: The Resource Allocation Influence the Profitability of the MSMEs

\begin{tabular}{lccccc}
\hline Statements & N & Min & Max & Mean & $\begin{array}{c}\text { Std. } \\
\text { Dev }\end{array}$ \\
\hline $\begin{array}{l}\text { Resource allocation is time consuming and costly } \\
\begin{array}{l}\text { The MSMEs have adequate physical and human } \\
\text { resources to promote organizational performance }\end{array}\end{array}$ & 87 & 1.00 & 5.00 & 3.505 & 1.256 \\
$\begin{array}{l}\text { It is possible to execute a strategy when resources } \\
\text { are inadequate }\end{array}$ & 87 & 1.00 & 5.00 & 2.885 & 1.261 \\
$\begin{array}{l}\text { Effective management of resource allocation could } \\
\text { lead to better performance }\end{array}$ & 87 & 1.00 & 5.00 & 4.069 & 1.179 \\
$\begin{array}{l}\text { Resources are crucial element for the successful } \\
\text { execution of strategic plan and strategies }\end{array}$ & 87 & 1.00 & 5.00 & 4.092 & 1.147 \\
\hline
\end{tabular}

\subsubsection{Innovation and Profitability of MSMEs}

The study attempted to determine the extent to which innovation influences the profitability of MSMEs. From the analysis in table 6, slightly majority of the interviewees $(62.1 \%)$ felt that innovation influences the profitability of MSMEs to a great extent, while $24.1 \%$ of the interviewees indicated that innovation influences the profitability of MSMEs to a considerable extent. However, $24.1 \%$ of the interviewees indicated that innovation influences the profitability of MSMEs to a moderate extent. The results are consistent with the outcomes by Hoang (2010) that in the modern SMEs have embraced various innovations including product, process and organizational innovations so as to improve their competitive advantage.

Table 6: The Extent to Which Innovation Influences Profitability of MSMEs

\begin{tabular}{lll}
\hline Statements & Frequency & Per cent \\
\hline
\end{tabular}


To a great extent

To a considerable extent

To a moderate extent

Total
100.0

From the results in table 7, majority of the informants strongly agreed that the MSMEs had adopted process innovation $(\mathrm{M}=3.7931, \mathrm{SD}=1.002)$, marketing innovation $(\mathrm{M}=3.7471, \mathrm{SD}=0.917)$, product innovation $(\mathrm{M}=3.7356, \mathrm{SD}=1.072)$ and that organization innovation $(\mathrm{M}=3.6437$, $\mathrm{SD}=1.078$ ). Different kinds of innovations are need to drive profitability of the MSMEs and especially marketing innovation which enable smaller firms to access global market. The results of the study collaborates the findings by Ainin, Parveen, Moghavvemi, Jaafar, and Shuib, (2015) that SMEs have embraced digital platforms such as Facebook, LinkedIn, and Twitter as a marketing strategy has the potential to bolster the performance through enhanced customer management and substantial decrease on marketing and customer service costs. Besides, IT resources support smaller firms to increase visibility via website, appeal and connects with potential customer at very lost cost (Otero, Gallego, \& Pratt, 2014).

Table 7: Various Forms of Innovation Adopted by the MSMEs

\begin{tabular}{llllll}
\hline Innovation & N & Min & Max & Mean & Std. Dev \\
\hline Product innovation & 87 & 1.00 & 5.00 & 3.7356 & 1.072 \\
Marketing innovation & 87 & 1.00 & 5.00 & 3.7471 & 0.917 \\
Process innovation & 87 & 1.00 & 5.00 & 3.7931 & 1.002 \\
Organization innovation & 87 & 1.00 & 5.00 & 3.6437 & 1.078 \\
\hline
\end{tabular}

Regarding the aspect of innovation, the research found out that most of the interviewees were in agreement that innovation is one of the vital elements for MSMEs to survive and flourish $(\mathrm{M}=4.160, \mathrm{SD}=0.679)$, innovation help in meeting the market needs and seizing new market opportunities $(\mathrm{M}=4.149, \mathrm{SD}=0.619)$, innovation strategy is a key driver of performance of MSMEs $(\mathrm{M}=$ 4.126, $\mathrm{SD}=0.728$ ), innovation capability can substantially alter MSME performance $(M=4.046, S D=0.805)$ innovation insulates enterprises against threats and competition $(M=4.057$, $\mathrm{SD}=0.853$ ), and that MSMEs have adopted latest technologies to improve the efficiency and quality of production $(\mathrm{M}=3.896, \mathrm{SD}=0.91)$. The results of this study collaborate the findings of Osorio, Lonono, and Lopez (2016) that SMEs that incorporate ICT in their communication and business model was capable of accessing and competing in markets with bigger firms. Furthermore, ICT offered SMEs a platform to access new markets, business information, and seize emerging opportunities and also aided the small firms to communicate with its customers more effectively. Moreover, the study outcome affirms the findings by Yang et al., (2015), and Eid and El-Gohary, (2013) that ICT is such an invaluable resource for small businesses to attain increased 
marketing successes via e-marketing and e-commerce, enabling of SMEs to seize business opportunities that legacy communication tools would not typically offer.

Table 8: The Influence of Innovation on Profitability of the MSMEs

\begin{tabular}{lrrrrr}
\hline & $\mathrm{N}$ & Min & Max & Mean & $\begin{array}{c}\text { Std. } \\
\text { Dev }\end{array}$ \\
\hline $\begin{array}{l}\text { The MSME has adopted latest technologies to } \\
\text { improve the efficiency and quality of production. }\end{array}$ & 87 & 2.00 & 5.00 & 3.896 & 0.915 \\
$\begin{array}{l}\text { Innovation is one of the vital elements for MSMEs } \\
\text { to survive and flourish. }\end{array}$ & 87 & 1.00 & 5.00 & 4.160 & 0.679 \\
$\begin{array}{l}\text { Innovation capability can substantially alter MSME } \\
\text { performance }\end{array}$ & 87 & 2.00 & 5.00 & 4.046 & 0.805 \\
$\begin{array}{l}\text { Innovation strategy is a key driver of performance of } \\
\text { MSMEs }\end{array}$ & 87 & 2.00 & 5.00 & 4.126 & 0.728 \\
$\begin{array}{l}\text { Innovation help the in meeting the market needs and } \\
\text { seizing new market opportunities }\end{array}$ & 87 & 2.00 & 5.00 & 4.149 & 0.619 \\
$\begin{array}{l}\text { Innovation insulates enterprises against threats and } \\
\text { competition }\end{array}$ & 87 & 1.00 & 5.00 & 4.057 & 0.853 \\
\hline
\end{tabular}

\subsection{Inferential Analysis}

The study adopted multiple regression to determine the influence of predicators on the dependent variable using SPSS software Version 21.0. The synopsis of the model is illustrated in Table 9. The coefficient of determination was utilized to determine the degree of variance between the dependent variable and independent variables in the study. R-squared is a statistical expression that show the ratio of the variance for a dependent variable that is accounted for by the predictors or independent variables in a model. The regression output exhibit a positive linear association between independent variables and dependent at $R=0.713$, hence the relationship between them is significant. The model's adjusted coefficient of determination $\left(\mathrm{R}^{2}\right)$ of 0.497 indicated that $49.70 \%$ of the changes in profitability in MSMEs was accounted for by resource allocation and innovation. The remaining portion of about $50.30 \%$ of the unexplained changes is accounted for by factors that were not within the purview of this study.

Table 9: Model Summary

\begin{tabular}{ccccc}
\hline Model & R & R Square & Adjusted R Square & $\begin{array}{c}\text { Std. Error of the } \\
\text { Estimate }\end{array}$ \\
\hline 1 & $.713^{\mathrm{a}}$ & .509 & .497 & .47997 \\
\hline
\end{tabular}

a. Predictors: (Constant), Resource allocation, Innovation

As illustrated in Table 10, the testing of the model's significance was pegged at 95\% confidence interval and 5\% significance level. The ANOVA output showed that the significance level of the model had a probability value of 0.000 which was lower than 0.05 and thus the model exhibited 
a less than 0.005 probability of yielding incorrect prediction. This shows that the model was significant and suitable for this study. Based on the ANOVA results, the study demonstrated that the regression model had a significance level of $0.00 \%$ that clearly showed that the data was perfect for making a generalization of the whole population parameters as the probability value was way below $5 \%$ for this study.

Table 10: ANOVA Result

\begin{tabular}{llccccc}
\hline Model & & $\begin{array}{c}\text { Sum of } \\
\text { Squares }\end{array}$ & df & $\begin{array}{c}\text { Mean } \\
\text { Square }\end{array}$ & F & Sig. \\
\hline 1 & Regression & 20.051 & 2 & 10.026 & 43.521 & $.000^{\mathrm{b}}$ \\
& Residual & 19.351 & 84 & .230 & & \\
& Total & 39.402 & 86 & & & \\
\hline
\end{tabular}

a. Dependent Variable: Profitability in MSMEs

b. Predictors: (Constant), Resource allocation, Innovation

As demonstrated in Table11, the study results showed that resource allocation and the profitability of MSMEs possessed a positive and statistically significant relationship $(\beta=0.139, \mathrm{P}=0.002$ $<0.05)$. This figure showed that that resource allocation positively influenced profitability of micro small and medium enterprises. It also suggests that a unit rise in resource allocation resulted to a growth in profitability of micro small and medium enterprises by 0.139 units. Moreover, Innovation was also found to be positive and statistically significant in explaining profitability of micro small and medium enterprises $(\beta=0.387, \mathrm{P}=0.000<0.05)$. This is an indication that innovation as a predicator positively influenced the profitability of micro small and medium enterprises. In addition, this illustrated that a unit growth in innovation caused an increase in profitability of micro small and medium enterprises by 0.387 units.

The regression analysis yielded the following equation:

$Y=\beta_{0}+\beta_{1} X_{1}+\beta_{2} X_{2}+\varepsilon_{i}$

Where: $Y=$ Profitability of MSMEs; $\mathrm{X}_{1}=$ Resource Allocation; $\mathrm{X}_{2}=$ Innovation

$\beta_{0}=$ The Regression coefficient; $\varepsilon_{i}=$ error term

Thus the equation becomes: $\mathrm{Y}=1.792+0.139 \mathbf{X}_{\mathbf{1}}+0.387 \mathbf{X}_{\mathbf{2}}$

Table 11: Regression Coefficients

\begin{tabular}{|c|c|c|c|c|c|c|}
\hline \multirow{2}{*}{\multicolumn{2}{|c|}{ Model }} & \multicolumn{2}{|c|}{$\begin{array}{l}\text { Unstandardized } \\
\text { Coefficients }\end{array}$} & $\begin{array}{c}\text { Standardi } \\
\text { zed } \\
\text { Coefficient } \\
\text { s } \\
\end{array}$ & \multirow[t]{2}{*}{$\mathbf{t}$} & \multirow[t]{2}{*}{ Sig. } \\
\hline & & $\mathrm{B}$ & Std. Error & Beta & & \\
\hline \multirow[t]{3}{*}{1} & (Constant) & 1.792 & .263 & & 6.824 & .000 \\
\hline & Resource Allocation & .139 & .043 & .256 & 3.239 & .002 \\
\hline & Innovation & .387 & .048 & .642 & 8.134 & .000 \\
\hline
\end{tabular}




\subsection{Summary, Conclusion and Recommendation}

\subsection{Summary of the Research Findings}

On the aspect of resource allocation, findings revealed that resource allocation had a positive relationship with profitability of micro small and medium enterprises. It also suggests that a unit rise in resource allocation resulted to a growth in profitability of micro small and medium enterprises. In addition, the study established that resources are crucial element for the successful execution of strategic plan and strategies, effective management of resource allocation could lead to better performance, and that the MSMEs have adequate physical and human resources to promote organizational performance. The study results revealed that resource allocation and the profitability of micro small and medium enterprises possessed a statistically significant relationship.

On the second objective, innovation was found to be statistically significant in explaining profitability of micro small and medium enterprises. This showed that innovation as a predicator positively influenced profitability of micro small and medium enterprises.Moreover,the study established that innovation influences the profitability of MSMEs to a great extent and that the MSMEs had adopted various forms of innovation, Moreover, the study also established that innovation is one of the vital elements for MSMEs to survive and flourish, innovation help in meeting the market needs and seizing new market opportunities, innovation strategy is a key driver of performance of MSMEs, innovation capability can substantially alter MSME performance, innovation insulates enterprises against threats and competition, and that MSMEs have adopted latest technologies to improve the efficiency and quality of production.

\subsection{Conclusion}

Based on the analyzed results concerning resource allocation, study concluded that resource allocation and the profitability of micro small and medium enterprises possessed a positive and statistically significant relationship. In addition, the study concluded that level of resource allocation in the MSMEs was moderate and that MSMEs were moderately resourced. Besides, the study concluded that resources are crucial element for the successful execution of strategic plan and strategies, effective management of resource allocation could lead to better performance, and that the MSMEs have adequate physical and human resources to promote organizational performance.

Finally, regarding the study concluded that innovation had a positive and statistically significant influence on profitability of MSMEs and that innovation influences the profitability of MSMEs to a great extent. Moreover, the study also concluded that innovation is one of the vital elements for MSMEs to survive and flourish, innovation help in meeting the market needs and seizing new market opportunities, innovation strategy is a key driver of performance of MSMEs, innovation capability can substantially alter MSME performance, innovation insulates enterprises against threats and competition, and that MSMEs have adopted latest technologies to boost the efficiency and quality of production.

\subsection{Recommendations}

From the foregoing, the study recommended, the study identified a number of recommendations to be instituted by management of these businesses in MSMEs industry. Study recommends that MSMEs should establish effective management and optimization of resource allocation since enterprises do not have unlimited access to resources. Furthermore, MSMEs are known to have 
finite resources and this could hamper their ability to implement strategic plan and strategies that are crucial drivers of competitive advantage and superior performance.

In respect of innovation, study recommends that MSMEs should embrace various form innovations including product, marketing, process and organization innovation which a considered as key driver of performance of MSMEs so that they can compete with larger firms owning significant resource both financial and non-financial resources. Furthermore, smaller business can incorporate innovation in its business model and strategy to protect it from threats and stiff competition from established firms by improving its efficiency and quality of production.

\section{References}

Barney, J.B. (1991). Firm resources and sustained competitive advantage. Journal of Management, $17,99-120$.

Bryceson, K., \& Slaughter, G. J. (2011): Aligning operational and corporate goals: A case study in cultivating a whole-of-business approach using a supply chain simulation game. Extension Farming Systems Journal, 7 (2), 7-16.

Bunyasi, G.W., Bwisa, H., \&Namusonge, G. (2014).Effect of Access to Business Information on the Growth of Small and Medium Enterprises in Kenya. International Journal of Business and Social Science, 5 (10): 121- 128

Eisenhardt, K. M. \& Martin, J. A. (2000). Dynamic capabilities: what are they? Strategic Management Journal, 21, 1105-1121.

OECD. (2016).Entrepreneurship at a Glance, OECD Publishing, Paris

Gure, A. K., \& Karugu, J. (2018). Strategic management practices and performance of small and micro enterprises in Nairobi City County, Kenya. Int. Acad. J. Hum. Resour. Bus. Adm, 3, $1-26$

Hitt, M. A., Ireland, R. D., \& Hoskisson, R. E. (2012). Strategic management cases: competitiveness and globalization. Cengage Learning.1398

Haines, S. (2016). The systems thinking approach to strategic planning and management. CRC Press.

Kothari, C. R. (2014). Research methodology: methods and techniques. New Age International.

M. Mohd Rosli and Syamsuriana S. (2013). The Impact of Innovation on the Performance of Small and Medium Manufacturing Enterprises: Evidence from Malaysia. Journal of Innovation Management in Small \& Medium Enterprise, Vol. 2013:1-16.

Mugenda, M. O. and Mugenda, M. A. (2013).Research Methods: Quantitative and Qualitative Approaches. Nairobi. ACTS Press.

Muogbo, U. S. (2013). The impact of strategic management on organizational growth and development (A study of selected manufacturing firms in Anambra State). IOSR Journal of Business and Management, 7(1), 24-32.

Ndiaye, N.; Razak, L.A.; Nagayev, R.; Ng, A.(2018).Demystifying small and medium enterprises“ (SMEs) performance in emerging and developing economies. Borsa Istanb. Rev. 2018, 18, 269-281. 
Newbert, S.L. (2007). Empirical research on the resource-based view of the firm: An assessment and suggestions for future research. Strategic Management Journal, 28, 121-146.

Noe, R. A., Hollenbeck, J. R., Gerhart, B., \& Wright, P. M. (2017). Human resource management: Gaining a competitive advantage. New York, NY: McGraw-Hill Education

Otero-Neira, C., Lindman, M. T. \& Fernández, M. J. (2009). "Innovation and Performance in SME Furniture Industries: An International Comparative Case Study," Marketing Intelligence \& Planning, 27 (2), 216-232.

Owolabi, S. A., \& Makinde, O. G. (2012). The effects of strategic planning on corporate performance in university education: A study of Babcock University. Kuwait Chapter of Arabian Journal of business and management Review, 33(853), 1-18.

Pearce, J. and Robinson, R. (2013).Strategic Management: Strategy Formulation Implementation and Control. 13th Edition, McGraw-Hill/Irwin, New York.

Saunders, M., Lewis, P. \& Thornhill, A. (2012). Research Methods for Business Students (6th edn), Pearson, Harlow.

Teece, David; Pisano, Gary; Shuen, Amy (August 1997). Dynamic Capabilities and Strategic Management. Strategic Management Journal. 18 (7): 509-533.

Tripsas, M. (1997).Surviving radical technological change through dynamic capabilities: evidence from the typesetter. Industry.Industrial and Corporate Change, 6(2), 341.

Varis, M. and Littunen, H. (2010). "Types of Innovation, Sources of Information and Performance in Entrepreneurial MSMEs. European Journal of Innovation Management, 13 (2), 128 154.

.Yazdanfar, D.(2013) "Profitability determinants among micro firms: Evidence from Swedish data," The International Journal of Managerial Finance, vol. 9, no. 2, pp. 150-160.

Zollo, M. \& Winter, S.G. (2002). Deliberate learning and the evolution of dynamic capabilities. Organization Science, 13(3), 339-351. 